\title{
Comportamento das Forças de Aderência do Adesivo Selante de Silicone e do Mastic Butílico
}

\author{
Wanderley da Costa \\ Departamento de Engenharia Metalúrgica e de Materiais, USP \\ Brascola Ltda, São Bernardo do Campo-SP
}

Leonardo G. A. Silva

Centro de Tecnologia das Radiações, IPEN-SP

Hélio Wiebeck

Departamento de Engenharia Metalúrgica e de Materiais, USP

\begin{abstract}
Resumo: A pesquisa demonstra como é o comportamento de dois materiais conhecidos comercialmente como mastic em relação às forças de cisalhamento de selantes. No mercado existem dois tipos de mastic, um da família de silicones e outro da borracha butílica. A pesquisa teve o objetivo de esclarecer junto à receita federal e ao mercado, que as propriedades dos dois tipos são muito diferentes, apesar de ambos sofrerem um processo de cura. Com o tempo há aumento das forças de coesão e adesão de ambos, o que evidencia o processo de cura.
\end{abstract}

Palavras-chave: Adesivo, selante, silicone, mastic butílico.

\section{Behavior of Adherence Forces of the Butyl Mastic and Silicone Sealant Adhesives}

Abstract: This study reveals the response to shear forces for two materials known as mastic. There are two kinds of mastic in the market, one of the silicone family and another made with butyl rubber. The aim was to demonstrate to the Inland Revenue and to the market that these materials exhibit very distinct properties, although both undergo the curing process. As time goes by, there is an increase in the forces of cohesion and adhesion for both types of mastic, which is evidence of the curing process.

Keywords: Adhesives, sealant, silicone, butyl mastic.

\section{Introdução}

$\mathrm{O}$ uso dos adesivos remonta desde a antiguidade. Essa arte consistia basicamente em se utilizar certos polímeros naturais como meio de se "colar" um determinado material em outro. Utilizou-se cola de origem animal, material asfáltico, resina de árvores entre outros, tudo isso muito antes da introdução das técnicas modernas, baseadas no emprego de amido vegetal, látex natural ou polímeros sintéticos.

Com o passar do tempo, desenvolveram-se adesivos sintéticos que apresentavam propriedades idênticas (senão melhores), transformando a antiga arte numa técnica aprimorada. Hoje em dia, vários fatores contam na escolha de um determinado tipo de adesivo:

1. os adesivos devem molhar a superfície em que serão aplicados;

2. se esta superfície for impermeável, e não absorvente, os adesivos deverão estar livres de água ou solventes orgânicos;

3. deverão ter custo baixo, tanto os adesivos quanto os métodos de aplicação;

4. os adesivos não deverão ser mais rígidos que o substrato, para que as tensões não se concentrem nos adesivos; e

5. após endurecerem, a junta colada deverá estar apta a resistir às condições ambientais.

Os endurecimentos de alguns adesivos podem ser efetuados do seguinte modo:

a. Resfriamento de um sólido fundido - Esse processo já era utilizado na Roma antiga para a confecção de barcos, sendo o betume o adesivo. Como por exemplo, cera de parafina reforçada com polietileno, usada para o revestimento de papéis que necessitam pouca permeabilidade à umidade. Os diácidos comercialmente importantes são dímeros ou trímeros de ácidos graxos insaturados, que se unem por meio das insaturações, os grupos amida dos polímeros assim obtidos dão boa adesão ao papel, couro, metais e borracha, e as cadeias alifáticas dão flexibilidade ao adesivo;

b. Técnica de evaporação do solvente - A adição de um solvente ao adesivo visa principalmente à redução de sua viscosidade. Assim, a água é usada para dissolver amido, dextrinas, cola de proteínas, silicato de sódio, PVA (poliacetato de vinila) etc. No caso de adesivos formulados com borracha natural regenerada, policloropreno, borracha nítrica, nitrocelulose e alguns polímeros vinílicos, utilizam-se solventes orgânicos. O uso consiste na aplicação de emulsão do adesivo em seu solvente na superfície a ser colada, faz-se pressão e, quando o solvente evapora, a colagem estará feita

Esta técnica é empregada em fitas gomadas, etiquetas etc., sendo os constituintes mais usados no preparo destes adesivos os polímeros citados anteriormente, uma resina aglutinante (politerpeno), antioxidantes, plastificantes (como o óleo mineral e a lanolina) e carga, como $\mathrm{ZnO}$ (óxido de zinco), $\mathrm{MgO}$ (óxido de magnésio) e $\mathrm{Al}_{2} \mathrm{O}_{3} \cdot 3 \mathrm{H}_{2} \mathrm{O}$ (óxido de alumínio hidratado); e 
c. Polimerização no local - Nesse caso, uma força de atração entre as moléculas que constituem o adesivo é obtida pela formação de ligações cruzadas entre elas. Pertencem a este grupo todas as resinas termorrígidas, como a resina ureia-formol, melanina-formol, a borracha de silicone, também denominado de vulcanização a frio, RTV (Room Temperature Vulcaning Vulcanização a temperatura ambiente), poliuretanos, etc. Outros adesivos dessa classe são as resinas epoxi. Os adesivos desse grupo possuem a vantagem principalmente depois de curados, apresentarem grande estabilidade dimensional, resistência a elevadas temperaturas e a solventes, em comparação com os demais adesivos.

Para as aplicações de mercado referentes ao adesivo selante de silicone, principalmente na construção civil, tem um fator importante na economia. A sua diversidade nas aplicações em vários materiais sejam para colar, vedar ou calafetar é de importância relevante, devido ao seu custo acessível. A sua versatilidade na aplicação é seu ponto forte. Seu sistema de cura é em função da umidade relativa do ar, tornando-se um produto muito prático e simples de ser aplicado.

O mastic butílico tem seu processo de cura por secagem pela evaporação de solvente, isto é, o solvente é um veículo que facilita sua aplicação.

\section{Silicona}

O principal componente das siliconas é o silício: o segundo elemento mais abundante da superfície da Terra, depois do oxigênio. A silicona foi descoberta pelo químico Johann Berzelius (1779-1848), na tentativa de sintetizar e reagir compostos com o silício. O uso do silício requer processos químicos muito complexos, que só começaram a ser desenvolvidos por volta de 1930 na Europa, precisamente em setembro de 1938. A descoberta das siliconas foi uma contribuição muito importante não só na área de adesivos, tintas, impermeabilizantes; mas principalmente na eletrônica, com a evolução dos computadores no vale do silício nos Estados Unidos da América. Para os cientistas, o mais importante foi tentar uma polimerização com um composto inorgânico, transformando $\mathrm{Si}-\mathrm{O}-\mathrm{Si}$ em Si-C, isto é, introduzindo compostos orgânicos, como por exemplo radicais metila $\left(-\mathrm{CH}_{3}\right)$ em uma estrutura inorgânica como a do silício ${ }^{[1]}$, como mostrado na Figura 1.

A tecnologia dos adesivos de silicona principalmente no enfoque analítico na busca de soluções alternativas é ao mesmo tempo ciência e arte. Desde a segunda guerra mundial, desenvolveram-se muitas substâncias para a fabricação de óleos impermeabilizantes, tintas, adesivos, revestimentos, espumas rígidas e flexíveis, entre outros produtos. A partir de 1940 a indústria de silicona dos EUA passou a ter importância, com a produção em larga escala destes produtos. Os primeiros selantes surgiram em 1958, com uma patente da Rhodia.

Devido à grande variedade de materiais que se pode obter, este foi o ramo na área de polímeros que mais se desenvolveu nas últimas décadas. Uma área de interesse na química do silício, além da eletrônica, é a de adesivos, onde se tenta resolver problemas específicos quanto à adesão de substratos, principalmente dos metais e plásticos de engenharia. Com suas excelentes propriedades de adesão, vedação, resistência a intempéries e química, as siliconas conquistaram mercados importantes como, por exemplo: construção civil, eletrônica, espacial e até mesmo o militar.<smiles>CO[Si](C)(OC)O[Si](C)(OC)OC</smiles><smiles>CO[Si](C)(C)O[Si](C)(C)C</smiles>

Figura 1. Estrutura inorgânica e inorgânica-orgânica do silício.
Bodnar $^{[2]}$ demonstrou o mecanismo da reação da silicona mono componente, como é feita sua cura no sistema RTV. Embora estes produtos são formulados para aplicações de selagem e recobrimento (tintas), eles são incluídos aqui porque um selante é essencialmente um adesivo de preenchimento de grandes espaços vazios, com uma viscosidade elevada. Mesmo agregando outras funções como selagem, vedação e calafetação, não deixa de ser um adesivo.

Leite $^{[3]}$ descreve claramente o comportamento da reatividade da silicona em várias temperaturas durante o processo de cura.

A avaliação destas juntas adesivas ${ }^{[4]}$ é comparada pelas forças de adesão na interfase dos materiais frente a diferentes aplicações.

\section{Mastic butílico}

Existem duas possibilidades de formular um selante baseado em borracha butil ou butílica, que são as principais borrachas do sistema mastic ${ }^{[5]}$. A primeira é usar uma borracha butílica com elevada massa molar, sólida, e que possa ser misturada com solventes e óleos plastificantes. A segunda possibilidade é misturá-la com polibuteno líquido, a característica de pegajosidade será predominante, podendo assim elevar o conteúdo de carga mineral para melhorar o custo. O produto tem seu processo de cura por evaporação de solvente tornando-se uma massa não secativa, isto é, não adesiva (colante). Esta característica em alguns casos é fundamental para alguns tipos de juntas de materiais. Tem-se como exemplo, a construção de estruturas metálicas de alumínio, carrocerias de caminhões baú, onde existem pequena movimentação mecânica, que no caso do adesivo poderia atingir a fadiga e comprometer não só a colagem como também a vedação ou calafetação. A movimentação mecânica e a resistência à umidade, barreira contra água ou infiltração, são algumas das particularidades que caracterizam o produto denominado mastic.

O mastic hoje é mais encontrado na construção de estruturas metálicas de alumínio. Quando se trata de custo é fundamental analisar as formulações ${ }^{[6]}$, existiram formulações com até $56,5 \%$ de cargas minerais na década de 70, com uma validade de 1 ano. Hoje com o avanço de novas matérias primas, pode-se atingir até $79 \%$. Por ser um produto não secativo sua validade pode chegar até dois 2 anos.

Estes selantes recebem várias denominações tais como: selante base butil ou butílico, mastic butil, mastic butílico ou simplesmente mastic. No mercado, obedecem a uma formulação básica, utilizando como polímero principal a borracha butil que varia de 1 a $3 \%$. Como se trata de um produto de simples mistura, a estrutura de formulação é basicamente a seguinte: 25 a $30 \%$ de óleos minerais ou naturais, 60 a $79 \%$ de cargas minerais, 0,05 a $3 \%$ de pigmentos, 7 a $18 \%$ de solventes e de 0 a $2 \%$ de aditivos. O polímero secundário é o poliisobutileno ou polibuteno, a quantidade varia de um fabricante para outro, de 1 a $2 \%$. O mastic é um produto não secativo e de formulação variável ${ }^{[7]}$ por causa da grande quantidade de óleo que compõe sua formulação e não apresentar agentes de reticulação, o mastic torna-se uma massa não secativa. Nas formulações de mastic não são encontrados agentes de reticulação, tais como: enxofre, óxido de zinco, óxido de magnésio, entre outros. Por esta razão o mastic butílico torna-se um produto com aspecto de borracha macia, maleável, semelhante a um chiclete, alguns tipos possuem aditivos para formar uma pele "casca", para protegê-los dos raios ultravioletas. Como por exemplo, o "Juntabel", um produto muito conhecido no mercado brasileiro, que se destacou muito na área da construção civil, na década de oitenta. A definição de mastic por outros pesquisadores ${ }^{[8]}$, são materiais que contêm óleos secantes ou componentes de betume, que com o tempo, também formam uma pele na superfície. Estes produtos fixam-se em vários substratos, sempre com o objetivo de preencher cantos ou junções com ângulos diversos. 
Este trabalho tem como objetivo demonstrar o comportamento da adesão por meio das forças de cisalhamento que atuam na superfície dos materiais. Seguindo a mesma linha de avaliação dos sistemas epóxi, tanto na cinética como em relação à cura ${ }^{[9]}$.

\section{Experimental}

Em ambas as amostras de produtos, foram utilizados chapas de alumínio (Alumi Copper 7075-T651, dureza $160 \mathrm{Hb}$ ) denominadas de corpo de prova. Os corpos de prova foram obtidos conforme a norma ASTM D 1002 ${ }^{[10]}$. Os ensaios foram realizados nos três períodos, 7, 14 e 28 dias após aplicação, para ambas as amostras. Com o objetivo de verificar o comportamento das forças de cisalhamento, isto é, o comportamento do sistema de cura (reticulação) dos sistemas. $\mathrm{O}$ equipamento utilizado foi uma máquina universal de ensaio Instron, modelo 3367, com célula de carga $30 \mathrm{kN}$ da empresa BRASCOLA. As amostras em estudo são produtos comercializados pela empresa BRASCOLA que recebem a seguinte denominação de mercado: BRASCOVED SUPER (silicone) e BRASCOVED 1513/CV (mastic). No experimento para melhor compreensão foram denominados de "silicone" e "mastic" respectivamente.

\section{Resultados e Discussão}

Os ensaios apresentados na Tabela 1 são referentes às amostras de silicone e mastic butílico, embora a norma peça 5 corpos de prova por amostra, foram realizados ensaios com 10 corpos de prova.

Os resultados mostrados nas Figuras 2 e 3 demonstraram os 3 períodos analisados e pode-se observar a evolução do sistemas de cura ao longo do tempo, isto sugere que as quantidades de ligações cruzadas estão aumentando com o tempo. Assim sendo, pelos resultados obtidos pode-se concluir que as forças de coesão entre os sistemas de silicone são bem mais intensas do que as dos sistemas butílicos. Os resultados da presente pesquisa são representativos e significativos dentro da área dos adesivos. Segundo alguns autores $^{[11-13]}$ a adesão pode ser definida como o estado no qual duas superfícies se mantêm unidas por forças interfaciais como forças químicas ou mecânicas, ou ambas. Por outro lado, um material adesivo é definido como uma substância capaz de manter unidos diferentes substratos por meio de uma superfície de fixação. Os ensaios de tração foram realizados com o objetivo de verificar as modificações das forças de cisalhamento da colagem de ambos os sistemas, no período de 28 dias, o quanto cada sistema teria de força de cisalhamento, no alumínio, no qual o silicone é muito utilizado na área da construção civil, para colagem de vidro em alumínio, observando também o comportamento do material com relação ao tempo de cura. No processo de cura de 28 dias, tem-se forças média de cisalhamento de $15,388 \mathrm{kgf} . \mathrm{cm}^{-2}$ para o silicone, enquanto que para o mastic butílico tem-se uma média de $0,378 \mathrm{kgf. \textrm {cm } ^ { - 2 }}$.

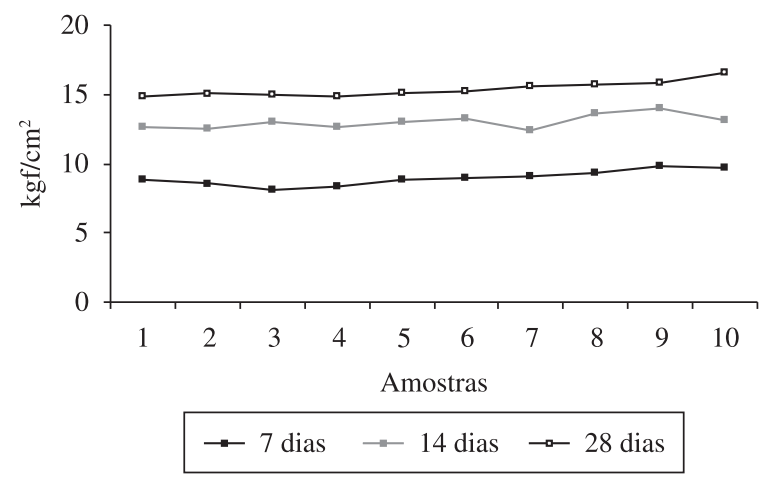

Figura 2. Força de cisalhamento silicone.

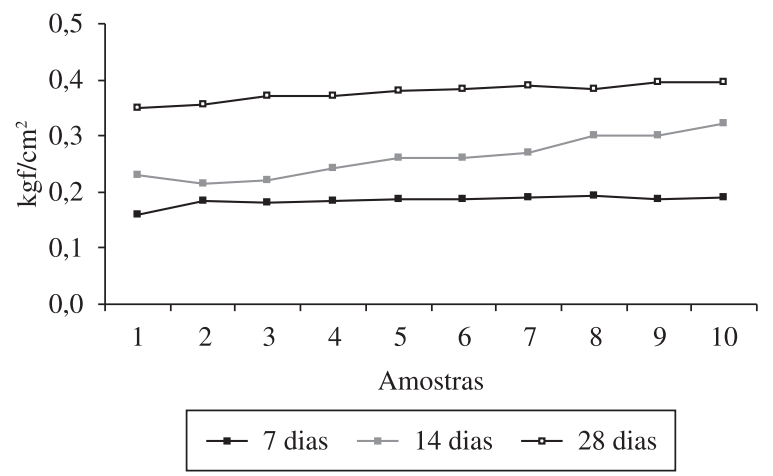

Figura 3. Força de cisalhamento mastic.

Tabela 1. Força de cisalhamento.

\begin{tabular}{|c|c|c|c|c|c|c|}
\hline \multicolumn{7}{|c|}{ Forças de cisalhamento $\left(\mathrm{kgf.cm}^{-2}\right)$} \\
\hline \multirow[b]{2}{*}{ Dias } & \multicolumn{3}{|c|}{ Silicone } & \multicolumn{3}{|c|}{ Mastic } \\
\hline & 7 & 14 & 28 & 7 & 14 & 28 \\
\hline \multicolumn{7}{|l|}{ Amostras } \\
\hline 1 & 8,853 & 12,621 & 14,839 & 0,161 & 0,231 & 0,351 \\
\hline 2 & 8,621 & 12,465 & 15,122 & 0,183 & 0,214 & 0,357 \\
\hline 3 & 8,121 & 12,978 & 14,989 & 0,181 & 0,221 & 0,371 \\
\hline 4 & 8,293 & 12,674 & 14,885 & 0,184 & 0,242 & 0,372 \\
\hline 5 & 8,776 & 12,983 & 15,063 & 0,187 & 0,262 & 0,379 \\
\hline 6 & 8,933 & 13,223 & 15,185 & 0,188 & 0,261 & 0,382 \\
\hline 7 & 9,023 & 12,386 & 15,634 & 0,191 & 0,271 & 0,389 \\
\hline 8 & 9,319 & 13,573 & 15,743 & 0,192 & 0,301 & 0,384 \\
\hline 9 & 9,805 & 13,927 & 15,842 & 0,187 & 0,302 & 0,395 \\
\hline 10 & 9,702 & 13,128 & 16,581 & 0,189 & 0,321 & 0,397 \\
\hline Média & 8,945 & 12,996 & 15,388 & 0,184 & 0,263 & 0,378 \\
\hline Desvio-padrão & 0,520 & 0,466 & 0,524 & 0,008 & 0,035 & 0,014 \\
\hline
\end{tabular}




\section{Conclusões}

Conforme a revisão da literatura e os ensaios realizados, pode-se concluir que o mastic de silicone estudado trata-se de um adesivo selante e o mastic butílico de um calafetador ou vedante. Pode-se afirmar que o sistema mastic butílico trata-se de um produto tendo como base a borracha butil, ou outros tipos de borrachas que combinam com a butil, óleos plastificantes, pigmentos e cargas minerais, tendo como principal característica a vedação e calafetação, apesar de evidenciar um sistema de cura com o tempo. Enquanto que o sistema silicone trata-se de um polímero que apresenta agente de cura e promotores de adesão, mantêm um sistema de cura que promove a colagem (adesão) de vários substratos, sendo esta sua principal característica. Os dois sistemas embora diferentes foram confrontados diretamente para comprovar suas forças coesivas intrínsecas e modificações das mesmas com o tempo de cura, bem como, entender a formulação do produto. Entre os dois sistemas estudados, pode-se afirmar que o silicone teve melhor interação adesiva com o substrato utilizado, apresentando em 28 dias, resultados satisfatórios para aplicações como adesivo. O mastic butílico comportou-se dentro do experimento como uma massa de calafetar e/ou vedar. Por esta razão este estudo contribuiu para uma classificação mais adequada quanto a definição para o mastic de silicone e o mastic butílico. Este trabalho é parte integrante de um estudo apresentado a ABIQUIM, para diferenciação da Tabela de Incidência do Imposto sobre Produtos Industrializados (TIPI) entre silicone e mastic butílico. Contribuindo para diferenciar o mastic silicone do mastic butílico.

\section{Agradecimentos}

A toda diretoria da empresa Brascola Ltda e a todos os colegas dos laboratórios de Pesquisa e Desenvolvimento e Inovação Tecnológica, especialmente o químico Edson Garcia Blanco.

\section{Referências Bibliográficas}

1. Liebhafski, H. A.; Liebhafski S. S. \& Wise, G. -"Silicones under the monogram”, John Wiley, New York (1978).

2. Bodnar, M. J. - "Structural adhesives bonding", Interscience, New York (1966).

3. Leite, C. A. P.; Castro S.; Soares R. F. \& Galembeck, F. - Polímeros, 5, p.23 (1995)

4. Garcia, F. G.; Sampaio, E. M.; Neves, A. F. \& Oliveira, M. G. Polímeros, 18, p.30 (2008).

5. Jackson, B. S. - "Industrial adhesives and sealants", Hutchinson, London (1976).

6. Flick, E. W. - "Adhesive and sealant compound and their formulations", Noyes, New Jersey (1978).

7. Houwink, R. \& Salomon, G. - "Adhesion and adhesives", Elsevier, Amsterdan, (1965).

8. Skeist, I. - "Handbook of adhesives", 2. ed.; Van Nostrand Reinhold, New York (1977).

9. Costa, M. L.; Rezende, M. C. \& Pardine, L. C. - Polímeros, 9, p.37 (1999).

10. American Society for Testing and Materials - "ASTM D1002: apparent shear strength of single-lap-joint adhesively bonded metal specimens by tension loading (Metal-to-Metal)", Philadelphia (2001).

11. Skeist, I. - "Handbook of adhesives", 3. ed., Ed.; Van Nostrand Reinhold, New York, (1990).

12. Buonocore, M. G. - J. Am. Dental Association, 67, p.382 (1963).

13. Lee, H. \& Orolowski, J. A. - "Adhesive dental composite restoratives", Lee Pharmaceuticals, South El Monte, (1973).

Enviado: $23 / 02 / 10$

Aceito: $19 / 07 / 10$

DOI: 10.1590/S0104-14282011005000013 